https://helda.helsinki.fi

\title{
Assembling Viability : The Art of Mundane Embryo Selection in IVF
}

\section{Helosvuori, Elina Inkeri}

2019-04

Helosvuori , E I 2019 , ' Assembling Viability : The Art of Mundane Embryo Selection in IVF ' , BioSocieties , vol. 14 , no. 1 , pp. 1-22 . https://doi.org/10.1057/s41292-018-0114-3

http://hdl.handle.net/10138/322545

https://doi.org/10.1057/s41292-018-0114-3

unspecified

acceptedVersion

Downloaded from Helda, University of Helsinki institutional repository.

This is an electronic reprint of the original article.

This reprint may differ from the original in pagination and typographic detail.

Please cite the original version. 


\title{
Elina Helosvuori
}

\section{Assembling viability: The art of mundane embryo selection in IVF}

\begin{abstract}
One of the mundane, everyday practices of IVF is observing and classifying embryos. After the fertilization, embryos are graded according to their quality which is an estimation of whether the embryogenesis - the embryo's development - seems normal or deviant. This practice is called embryo selection and it is based on assessing the 'good quality' embryos as viable and 'poor quality' ones as inviable. Viability refers to the capacity of embryos to develop into foetuses and eventually become babies. However, the question of what kinds of embryos ultimately are viable is a complex issue, which also hinges upon several other factors than the quality estimation. This paper shows that the idea of embryo viability is an assemblage of multiple kinds of things. The paper is based on multi-sited ethnography and expert and patient interviews conducted in the private fertility service sector of Finland. I argue that embryo viability is a practical achievement that requires the successful combination of several factors: the scientific facts on embryo quality, the expert knowledge and laboratory practices, and the patients' engagements in the process. None of these factors alone is enough to explain the precarious embryo viability which nevertheless is the central issue in IVF.
\end{abstract}

Keywords: IVF, embryo selection, viability, laboratory practices, ethnography

In the process of in vitro fertilization (IVF), the fertilization between an egg and a sperm takes place in a Petri dish outside the female body. If the fertilization succeeds, an embryo or multiple embryos 
start to develop in the dish. After fertilization, embryos are graded according to their quality, which is an estimation of whether the embryogenesis - the embryo's development - seems normal or deviant. This practice is called embryo selection and it is based on assessing the 'good quality' embryos as viable and 'poor quality' ones as inviable.

In the biological literature on human reproduction, embryo viability refers to the capacity of embryos to develop into foetuses and eventually become babies (e.g. Kieslinger et al, 2016). Only embryos that are viable enough can be used in IVF treatment. In order for the embryos to stay on the "pregnancy trail" (Cussins, 1996) of IVF, embryos have to be considered as holding the potential of becoming children. However, the question of what kinds of embryos ultimately are viable is a complex issue, which hinges upon several factors in addition to the quality estimation. Based on a multi-sited ethnography (Marcus, 1995; Falzon, 2009; Hannertz, 2003; Wittel, 2000) conducted in the private fertility service sector in Finland, this paper shows that the idea of embryo viability is an assemblage of scientific facts on embryo quality, laboratory practices of doing selection and patients' engagement and choices on what to do with particular kinds of embryos. ${ }^{1}$

The issue of selection and the specificities of selective technologies have been widely addressed in social scientific literature on IVF. Regarding embryos, these discussions have focused, in particular, on the selection concerning genetic diseases and other anomalies: Technologies of pre-implantation genetic diagnosis (PGD) and pre-implantation genetic screening (PGS) are conducted to avoid implanting embryos with genetic or chromosomal abnormalities. In the area of genetic selection of embryos, these technologies have been explored, for example, to analyse the objectives of implanting only "healthy embryos" (Nisker et al, 2010) and the ethics of screening carrier embryos (Ehrich et al, 2007) in hereditary illnesses such as breast cancer (Huijer, 2009). In addition, the implications generated when the sex of an embryo is selected before implantation (McGowan and 
Sharp, 2013; Scully et al, 2006) and the urge for creating embryos that could become "sibling donors" (Hashiloni-Dolev and Shkedi, 2007) have been addressed. Rather than overcoming infertility, selective reproductive technologies (SRT) such as PGD and PGS are conducted to "prevent or allow the birth of certain kinds of children" (Gammeltoft and Wahlberg, 2014, 201). The extreme nature of such selection has been widely debated in various national regulatory bodies (Pavone and Arias, 2012), as well as in media discussions on the ethics of the 'designer-baby' technologies, making possible the favouring of some features over others for possible children (Franklin and Roberts, 2006).

However, the mundane aspects of the selection in routine IVF treatment has gained limited attention compared to the more provocative selection of genetic technologies. ${ }^{2}$ The aim of this paper is hence to analyse how embryos become viable or inviable in the day-to-day practice of IVF. The focus is on embryo selection in its mundane form where embryos are observed, classified, transferred, stored and destroyed as part of IVF clinic services that are conducted routinely for pregnancies to begin in the first place. The selection practices explored in this paper aim for the best possible outcome of IVF in cases where there are multiple embryos to choose from. However, although IVF has become a highly routinized technology, its implementation nevertheless contains multiple negotiations and complexities (Lie and Lykke, 2017), which I show to be also constitutive of the embryo selection process. Selecting the right embryo is a complex process involving, for example, microscopes, embryologists, PGD/PGS embryo screening techniques and patients. Indeed, which embryo is the right embryo is always an achievement every time an embryo transfer decision is to be made.

In relation to the prior work on selective reproductive technologies (SRTs), the contribution of this paper lies in showing that the technology used in the selection has an essential role in embryos 
becoming viable or inviable in the lab, since the biological markers of viability can only be understood in relation to the techniques used in teasing them out. Different technologies explore different features of the embryos, and, for example, an embryo may seem as viable on morphological grounds assessed visually, but not on genetic grounds analysed in PGD. I argue, thus, that embryo viability is a practical, situated achievement that requires a successful combination of several factors: the scientific facts on embryo quality, the expert knowledge and laboratory practices, and the patients' engagements in the process. None of these factors alone is enough to explain embryo viability, which nevertheless is the central issue in IVF.

To capture the practical "doing" of embryo selection, I propose to use the concept of embryo viability. The aspects of embryo viability are widely discussed in the biological literature (e.g. Gardner et al, 2000; ALPHA and ESHRE, 2011) and among the experts of fertility treatments. In the scientific and clinical discussions, embryo viability refers to the process of embryogenesis - the embryo's development - being normal or deviant. As stated by Sarah Franklin (2013), in vitro embryos can be seen as "living tools" that reproduce biology, while opening it up to multiple uses and understandings. The biological process of embryogenesis as discussed in this paper, thus, manifests, how "biology as technology" is both stabilized and negotiated in the working world of doing embryo selection in the lab. ${ }^{3}$

My use of the concept embryo viability is empirically driven. I consider embryo viability as an open category in the sense that it is constantly actively "done" in the IVF clinics. I aim to develop embryo viability as an analytical notion that contributes to the social scientific literature on SRTs, and use the concept to highlight embryo viability as an uncertain and negotiated process. Whether a particular embryo is viable or not cannot be guaranteed by the physicians or the biologists working at the fertility clinic. Embryo viability is a biological quality that, while being stabilized to some 
extent, is also actively done in the IVF clinics. By my use of the concept of viability, I aim to capture the inherent uncertainty of the embryo selection practice, and show that conducting embryo selection demands situated and negotiated management of the uncertainties of embryogenesis, the viability of the embryo and its fate in treatment.

A distinctive focus in the discussion of selection in the assisted reproductive technologies (ARTs), and at the core of this paper, is the engagement of the patients in the process. For example, Sarah Franklin and Celia Roberts $(2006,152)$ address how intended parents seek to use PGD, the technique of analysing cell biopsies from embryos before implantation, as their last resort after suffering from actual or afraid for the loss of a child or an unborn carrying a fatal genetic disease. It has been argued that health-care authorities often emphasize reproductive self-determination of the patients in these situations to distance themselves from the eugenic past of selection in reproduction (Gammeltoft and Wahlberg, 2014, 204; see also Meskus, 2012). This paper argues that patients are also engaged in the process of embryo selection in the 'basic' procedure of selecting embryos on a visual and morphological basis rather than on genetic grounds.

I show how patients are enrolled in the process of selection by sharing information between experts and patients about the selective technology and about the biological markers of viability. In the private fertility clinics of Finland, patients as customers are informed of the morphological features of their developing embryos, if they wish to be. In this everyday information distribution to patients, patients gain skills about the technical details of the mundane technology. Furthermore, patients discuss these details with their peers on peer-support forums. I suggest that through such practices, patients become enrolled in the mundane selection process - without it actually being the clinics' intention. Patients do not, however, only learn to speak about embryo quality like experts. Besides gaining skills on the technologically assessed biological quality of the embryos, patient 
engagement may, as I will show, also occur in the form of making decisions on what to do with particular kinds of embryos at the end of the selection processes. Furthermore, the experts may reconsider their standards on embryo quality after surprising treatment results in following patients' decisions.

\section{Embryo viability as an achievement inside and outside the lab}

My analytical approach to embryo selection, and to embryo viability has been developed in relation to theorizations on the role of practices in scientific knowledge production and the ontological state of the objects of biomedical research. To analyse how embryo viability is achieved by doing embryo selection, I draw from Annemarie Mol's (2002) work on the "praxiographic turn": turning the focus from epistemological questions into enacting different realities or objects - such as embryo viability - in practices (see also Helén, 2011). In the words of John Law (2010 [2004], 159) enactment refers to "the claim that relations, and so realities and representations of realities [...] are being endlessly or chronically brought into being in a continuing process of production and reproduction [...]". I apply Mol's thought by exploring embryo viability as a process of enactments. For example, assessing embryo viability in the lab, or discussing it in peer-support groups, is part of the enactment process.

Since the lab is at the centre of my study, in addition to Mol's theorization on enacting realities in practices, I also draw from the tradition of laboratory ethnographies as an additional way of understanding embryo viability as a practical achievement. The classical laboratory ethnographies in science and technology studies (STS) focus on the construction of scientific facts and argue that it is grounded in the situated and material cultures and practices (e.g. Latour and Woolgar, 1986; Lynch, 1985; Knorr-Cetina, 1981; on more recent laboratory studies see Meskus, 2018). Indeed, 
these studies state that "the daily activities of working scientists lead to the construction of facts" (Latour and Woolgar, 1986, 40). In this paper, embryo viability is the "scientific fact" that needs to be explained by following the daily routines of conducting mundane experiments of transferring certain kinds of embryos and trying to understand the uncertainties of embryogenesis. In other words, embryo viability is a "fact" attached to the practices of embryo selection and clinical treatment routines.

Bruno Latour and Steve Woolgar describe scientific activity as "a fierce fight to construct reality" and the lab as "the workplace and the set of productive forces, which makes construction possible" (Latour and Woolgar, 1986, 243 original emphasis). In their analysis, the construction of reality is, thus, entangled with the laboratory practice. However, in his critical review, Park Doing (2008) argues that the iconic laboratory studies, such as Latour's and Woolgar's Laboratory life, nevertheless are not precise enough in their description of the construction of scientific facts in the lab. Doing argues that Latour and Woolgar explain the final becoming of facts with elements "from outside the immediate life-world of laboratory practice" (Doing, 2008, 286, original emphasis), such as the mentality of the scientists. It could be suggested, then, that the classical laboratory studies (e.g. Latour and Woolgar, 1986; Lynch, 1985; Knorr-Cetina, 1981) and their critiques (e.g. Doing, 2008) struggle to determine which situated elements produce particular scientific facts, and if they exist primarily inside or outside the sites of study, the laboratories (see Latour, 1983).

In comparison to the pioneering studies conducted in research laboratories, my study is based on embryo selection in laboratories whose main function is to conduct clinical treatment. In the clinical setting of my study, the question of 'internality' and 'externality' is posed in a slightly different manner because to understand what happens in the daily routines of embryo selection, it is necessary to include 'external' elements such as patient engagement to explain the enactment of 
viability in the lab. Indeed, in the case of embryo selection, the crucial 'external' role falls to the patients, since the routines of embryo selection are attached to their clinical treatment. I suggest that patients' engagement in the form of, for example, sharing videos about embryos' development in the first few days after the fertilization (see Van de Wiel, 2017) is incorporated into the circumstances in which the embryo viability is enacted. Indeed, embryo viability exceeds expert knowledge in the sense that it includes engaging patients in the selection process by, for example, discussing the quality of their embryos in clinical relations.

\section{My study}

Before moving on to the empirical analysis, I will elaborate in more detail my research data. The study is based on a multi-sited ethnography conducted in Finland. The fieldwork consists of participant observation conducted in two and expert interviews in four private fertility clinics in the metropolitan area of Finland. The clinics are typical in the group of private clinics situated in the large cities of Finland, aiming to provide cutting edge services especially for their heterosexual customers suffering from infertility. Concerning embryo selection, they apply situated, variant methods and policies. The focus of this paper was chosen based on the embryo selection methods I was able to observe in clinics 1 and 2 . In total, I conducted 7 semi-structured interviews and one group interview (with 3 therapists) with experts including doctors (2), biologists (2), therapists (4) and nurses (2).

In addition, the data includes participatory observation conducted in four face-to-face peer-support groups organized by a Finnish infertility association for people experiencing involuntary childlessness. I followed the groups during a period of 7 months. These groups gathered monthly to discuss childlessness, and their formation was based on diverse premises. One of the groups was 
directed to those who do not have any children. The majority of the group members were women, who were undergoing infertility treatment. The second group was for people who have used or are considering using donated gametes in IVF. The third group was for those, who have become parents, but, nevertheless, experience childlessness. The fourth group was for women who do not have a uterus. A majority of the group-members in all of the groups were women. Men who attended the groups during my fieldwork participated in the sessions with their female-spouses. No same-sex-couples attended the groups during my fieldwork.

During the fieldwork I conducted 13 in-depth interviews with 11 women and one male-female couple who have experienced infertility or IVF. In addition, I attended 10 expert and/or layperson conferences or other events on infertility and childlessness. I gathered the data from March 2013 to April 2015. All of my interviewees were given an informed consent form to sign. The participants of the peer-support groups gave an oral consent for my study.

The empirical story of this paper follows the three phases in the embryo selection: firstly, observation and grading of embryos in the lab; secondly, communicating and exchanging impressions on embryo quality between clinicians, IVF-biologists and patients and their possible therapists specialized in infertility; and thirdly, decision making on whether or not an embryo transfer should be conducted with the available embryos.

\section{The technology of selection}

To get a grip on how the process of achieving embryo viability proceeds, let us now enter the laboratory. The first phase of embryo selection, what I call 'the art of seeing', begins when the in vitro fertilization has taken place and the observation in the laboratories begins. Here enter the 
'simplest' procedures of selection: placing embryos under the microscope and observing them visually. In clinics 1 and 2, IVF-biologists hold the key role in determining whether or not an embryo could develop into a foetus and eventually become a baby. ${ }^{4}$ To analyse the elementary role of the technology of selection in making particular enactments of embryo viability possible, in this section I will juxtapose the mundane technology with other ways of selecting embryos.

The technology used in labs forms the basis of embryo viability. To do embryo selection in clinic 1 , IVF-biologists need a microscope, a screen and the possibility to make notes:

It is 7.30 AM, and routine embryo monitoring in the laboratory begins. Two biologists take part in this. One of them sits beside a microscope, the other one near an incubator where the embryos are stored throughout their time at the laboratory; they only spend a little while under the microscope. The microscope is connected to a screen, where also I as an observer am able to see the cells. One of the biologists has some papers in hand. She reads off some numbers, and the other one takes an embryo under observation accordingly. The papers at hand also include some previous records of the cells, this is not the first day they have looked at these particular cells and embryos. Today, the biologists have day 2 and 5 (after fertilization) embryos that have to be checked. "O how awful, that is one cellular", they say when one of the embryos appears on the screen. "Well that one is 5 cellular", no fragment, nucleuses are different size, they discuss regarding another one. "Put that as a three" they conclude with a third one. By now they have lost me on whether they have an embryo that has three cells or an embryo that is class three in quality. (Field notes from lab, May 2014.)

In the snapshot above, IVF-biologists are checking how many cells the embryos have, the cellular size and shape, and how much unwanted fragmentation there is (a sort of graininess in the structure of the embryo). These visually observed characteristics mark the progress of embryogenesis. They are the ones becoming visible during the observation and the ones affecting how embryo quality is estimated. Indeed, in order to conduct selection as described in this snapshot, "the eye needs to be 
taught to see", as some of my informants expressed it when embryo selection was discussed in a conference organized by The Nordic IVF-Laboratory Society (Helsinki, August 2013).

The visual images of cells, gametes and embryos, spreading also, for example, as 'YouTube' videos, are a prominent feature of IVF (Franklin, 2013, 249; Lie, 2015). In regards to selection, Lucy van de Wiel (2017) has analysed Time-Lapse embryo imaging, which adds yet another layer in the shared imagination of the beginning of life after the implementation of IVF (Franklin, 2013). The Time-Lapse imaging apparatus is an alternative technology for cultivating embryos in a device that includes recording cameras. In relation to the traditional method described in this paper, Time Lapse makes it possible to observe and analyse embryos without taking them outside incubators and under the microscope. Van de Wiel $(2017,292)$ argues that watching videos of their embryos before implantation "allow intended parents to share in the embryologists' gaze" and witness the cell divisions.

In time-lapse technology and the selection conducted with a microscope, embryos emerge as holding particular markers of viability or inviability that become visible for the biologist and possibly also for the intended parents. This intensifies the visual culture of IVF that the patients and laypeople can also witness as part of treatment, or by seeking information from the internet. As seen in the previous quotation from my field notes, the only way that the biologist in an IVF clinic can say something about the cellular size, shape and fragmentation of the embryo - that is, its quality is to have a look through the microscope. The quote illustrates that to achieve embryo viability depends on the imaging technology used in the clinics. By sharing the images between experts and patients, patients can also try to understand and imagine embryogenesis in a certain way. This enrolls patients into the world of embryo selection, in the sense that they gain information about its details. This sharing and distributing of information about embryo quality shows that selection is 
activity based on the collaboration of multiple factors: the scientific facts of embryo quality, the expert knowledge and laboratory practices as well as a patient's engagement. Later in the paper, I will show how patient enrolment takes place by way of patients gaining the skills to understand embryo quality through witnessing experts' actions. Another way this takes place is when patients become more active participants, when they may disagree with the experts' decisions to transfer the embryos or not.

Meanwhile, it should be noted that assessing embryo viability visually is not the only way to gain expert understanding of embryogenesis. When I first met a key informant of my study, the head of clinic 2, he told me that a new method of selection, pre-implantation genetic screening (PGS) that includes analysing a biopsy from an embryo, has revealed the weaknesses of only visually observing embryos with a microscope:

One of the main reasons why a pregnancy won't begin, or for a likelihood of 20, 30, or 40 percent at best, is that, although there could be a really good looking embryo, it may still carry chromosomal and genetic abnormalities that prevent it from developing [...]. Also in the good prognosis group, women under 35 years, even up to half of the so-called good looking embryos are nevertheless genetically deviant. That explains why all the clinics around the world conduct quite many treatments in vain, due to current methods. (An interview with a physician, May 2013.)

This citation illustrates, again, the signature role of the specific technology used in the lab in determining what can be observed in embryo selection. Embryo viability is enacted differently in PGS than in the mundane procedure of selection which testifies to that embryo viability is an achievement that needs to be assembled during the course of the treatment (also Svendsen and Koch, 2008). In other words, the markers of an embryo's quality exists only in relation to the 
technology used in teasing them out. An embryo may be assessed as viable when it is observed under the microscope, but inviable when the embryo biopsy is analysed.

In the working world of the labs 1 and 2, embryo quality is in the open-ended process of enactment. In conferences for the lab personnel, IVF-biologists often debate the markers of embryo quality, disagreeing on the viability of certain kinds of embryos (on disagreements, see also Ehrich, Williams and Farsides, 2010, 2207). During my fieldwork, I attended a conference organized by The Nordic IVF-Laboratory Society (Helsinki, August 2013). In their presentations, the participants of the conference reiterated that what worked in their lab may not work in somebody else's lab. "Create your own model" they encouraged one another.

For example, in one of the clinics where I conducted interviews, practices concerning embryos that have more than two nucleuses in the early phase of development have changed. Earlier, two nucleuses was taken as a serious marker of pathological embryogenesis. However, the clinic's statistics have shown that also these embryos may result in healthy pregnancies. Previously, embryos with certain features have been thrown in the bin although later practice has shown that these embryos may nonetheless be viable. This exemplifies how the understanding of how an extranucleus affects embryo viability is rewritten by the actual act of doing embryo selection.

To sum up, embryo viability is, partly, a result of the production of biomedical facts pertaining to the embryo. The achievement of embryo viability includes the construction of facts, such as the meaning of an extra nucleus for the viability of an embryo, in the daily practices of a clinical lab. The technology used and the methods of selection that are applied play a key role in determining which embryos are assumed to be the right ones for embryo transfer. In what follows, I elaborate in 
more detail how the IVF-biologists co-operate with the technology to achieve some closure on the question of whether an embryo is viable or not in the first phase of embryo selection.

\section{"We do not have facts": selection as an intuitive process}

The practice of observing embryos through the microscope and classifying them by their quality is an attempt to grasp the precarious, uncertain nature of embryo viability. The art of seeing embryo viability through the microscope testifies to the experts' embodied skills. Indeed, embryo viability is not a simple issue. Based on ethnographic fieldwork conducted in a Danish fertility clinic, Mette N. Svendsen and Lene Koch (2008) explore how complex decision-making processes constitute embryos as spare and enable their donation for stem cell research, if patients give their consent to it. Svendsen and Koch argue that spare embryos - the ones that are not used in IVF - are not straightforward biological facts. For example, experts hold conflicting responsibilities to conduct treatment but also to provide embryos for research. Hence, they negotiate their way through these positions, and they always find some conclusion on what to do with the embryos. Likewise, based on qualitative interviews conducted with members of clinic staff, those who approach couples who might have spare embryos in the UK, Kathryn Ehrich, Clare Williams and Bobbie Farsides (2010) suggest that not only technical but also social and moral meanings are inherent in categories of spare and viable embryos, that is, those that can be donated to research and those that should be used in IVF.

In line with these studies on embryo selection and the complex factors affecting the fate of the embryos in IVF, I turn now to the question of how IVF-biologists find their own ways to understand the process of embryogenesis. During my fieldwork in clinics 1 and 2, I learned that "an intuition is necessarily involved" in making clinical decisions about IVF treatment. A physician 
also described to me how "it is not at all only numerical, anatomic facts" that matter, but "rather a certain kind of impression emerges" on what should be done in IVF in a given situation. The physician referred to the Swedish colleagues who use the expression "Läkarblick" [physician's gaze] to describe the hunch that develops when the experience of an expert increases. Likewise, in a lab, IVF-biologists do embryo selection intuitively:

I'm sitting in a sperm lab with one of the IVF-biologist. We are waiting for a device to wash and handle a sperm sample just delivered. We begin to discuss embryo selection. "It feels funny to say this but many times we do not have facts" the biologist begins. What she means is that sometimes it is hard to describe on what basis the selection is made, although it is based on expertise. "There was something in that, some exciting thing" the biologist goes on to describe the feelings that the best-looking embryos provoke. She continues to explain how biologists observe the embryos in a Petri dish with a microscope. "Not that one, not that one", they may think when particular embryos are taken under observation. They may ask a colleague to have a look as well. Usually the colleague gets "the same feeling" from the cells. When an embryo is selected, "you make the decision and hope that you made the right one. You based it on something in that moment", the IVF-biologist concludes. (Field notes from lab, May 2014.)

The clinics that took part in my study use the morphological criteria for embryo viability described and debated in the biology literature as their guidelines for selection. In addition, the clinics conduct careful quality control themselves by compiling statistics about the embryos transferred and about the treatment results. However, in the working world of the lab, assessing embryo viability is not exclusively based on standard criteria but it also includes significant interpretation based on, what my informants called, intuition and feeling for the art of selection. Due to the inherent uncertainty of the process of embryogenesis, different IVF-biologist may also interpret the biological markers of viability differently, as I was told by the head of the laboratory in one of the clinics I conducted interviews. It was also regularly emphasized by my expert informants that the IVF clinics differ between one another in some of the criteria they use for selection. As an IVF-biologist that I 
interviewed described the situation, the one thing in common between clinics is, though, that nobody transfers "dead embryos".

Scientists working with living biological material in the lab have a tendency to develop affective relationships to that material, hence the craftwork of scientists is based on embodied and emotional investments (Meskus, 2018). Also the IVF-biologist described to me that good and bad quality embryos provoke different kinds of feelings in them. When an embryo selection is done in a specific lab, IVF-biologists may think aloud and describe how embryo quality looks "in my eyes". As part of doing embryo selection, embryos are described as "pretty", "beautiful", "smart looking ones", "regular", "not too bad", "poor" or "lousy" (on naming the embryos see Meskus, 2015). At best, embryos can be "sacrilegiously beautiful" in the eyes of the IVF-biologists. Good-looking embryos are considered as viable and bad looking ones less viable or totally inviable. These assessments highlight, again, the visual nature of selection and how the process is often based on practical intuition and impressions. While the uncertainties of embryogenesis result in fluidity in the classification system of embryos (Ehrich et al, 2010, 2207; Ehrich et al, 2008), the IVF-biologists have to nevertheless make decisions on viability and complete the embryo selection. As experts of embryo selection the biologists aim to stabilize the process of embryogenesis by grading the embryos regardless of their uncertainty.

Although the impressions on embryo viability may be vague, the routine to tackle the uncertainties of embryogenesis is clear: In clinic 1, embryos are observed until the time they ought to have developed into so-called blastocysts. At best, this is the case in day five after fertilization (the day the eggs and sperm are placed in a Petri dish is called day zero). The fertilization ought to happen by day one, when the IVF-biologist takes the cells outside the cultivation device and checks whether this is the case. The embryos are observed also in day two after fertilization, and during 
that day, the personnel observe whether fertilization has resulted in a living embryo or multiple ones. If it has, embryos are "left in peace" for day three and four. Finally, on day five, the IVFbiologists hope to see certain kinds of blastocysts. The selection of embryos with certain features indicating viability by the biologists represents how also the routine IVF can be seen as a practice of giving nature "a guiding hand", a phenomena that Ayo Wahlberg and Tine M. Gammeltoft (2018) argue to be the new paradigm of the selective reproductive technologies of the 21 st century.

To give a statement about embryo viability IVF-biologists have a look through the microscope and make notes based on what they see. In clinic 1, the final act to achieving a closure on the question of viability is to grade embryos on a scale of four categories. In a basic procedure, the grading begins when the embryos have achieved the state of blastocysts. This is also the day when the embryo transfer to a female patient's womb or to the freezer should be conducted - unfrozen embryos should not spent much more than five days outside the female body.

Early in the morning of day five, the grading begins. Grading completes the conducted observations, and the best-looking embryos are graded as "top" quality: A-class. With A-class embryos there are high hopes for the pregnancy to begin - although it may just as well not begin. The rest of the embryos fall along a continuum that ends with D-class. Embryos graded as A, B or $\mathrm{C}$ can be used in IVF, as they are considered viable enough. IVF-biologists and physicians do not recommend D-class embryos to be transferred to the uterus nor frozen to be used in another possible treatment cycle since they are considered inviable. Ultimately the use of the D-class embryos is, however, not solely the clinicians' decision.

The routine of grading embryos shows how the experts handle the liminal (see Squier, 2004) figure of an embryo. However, crucial phases in the process of achieving embryo viability are yet to come. 
During and after the first phase of embryo selection, communication about embryo quality to and between patients occurs. Patients of private fertility clinics are eager to know, how the embryos are doing during the cultivation in the lab. Outside the walls of the fertility clinics, patients are waiting for the phone to ring and to get good news on viable embryos that could then lead to fervently hoped for pregnancy. The sustained uncertainties in the ordinary embryo selection open up the possibility for the patients to engage in the process of selection, and ultimately in decision making on what to do with the embryos, like they do in the difficult situations of implementing highly selective techniques like the PGD. Thus, in the end, embryo viability is a negotiated, practical achievement.

\section{The phone calls from and to the lab}

The second phase of embryo selection consists of making sense of embryo viability by discussing it in the clinic. When embryo quality is discussed between experts and patients as part of the treatment routines, I suggest that patients are enrolled also into the process of enacting embryo viability. The fact that the experts describe embryo quality to the patients, for example in telephone discussions, and that these accounts linger in the experiences of the patients ( $\mathrm{NN}$, forthcoming), serves reaching towards a mutual goal: accomplishing the process of embryo selection. The communication is a crucial step in including patients in the process of selection, and sometimes also towards the patients' final decision on what to do with the embryos, as I will show later in the paper.

In the private IVF market, patients are positioned as customers who are faced with decisions on what selective techniques to apply in their reproduction (Martin, 2014). The ambivalence experienced by women in the area of reproduction and especially in the tentative pregnancies has 
been elaborated in many studies (e.g. Rothman, 1986). Women struggle and long for collective support, when having to make decisions about selection concerning prenatal screening and the possibility of terminating their pregnancy in case of foetal anomaly (Meskus, 2012). The decisions concerning embryo selection add to these reproductive choices (see also Gammeltoft and Wahlberg, 2014; van de Wiel, 2017).

Concerning embryo selection, patients are put in a situation where they are faced with the questions of what they want to do with certain kinds of embryos - do they, for example, want a bad quality embryo to be transferred or be disposed of. Both of these options may hold disadvantageous implications for the patients (cf. Mol, 2008), as transferring bad quality embryos may lead to conducting treatments "in vain", without reasonable likelihood for success, and the disposal may result in the perishing of embryos that might nevertheless have had a chance to result in a pregnancy. The second phase of embryo selection, I propose, initiates patients into the events of embryogenesis by sharing information.

During the process of IVF, patients are informed by the clinics' staff of how their embryos are performing in the lab. In my field work clinics, when the process of embryo selection is ongoing the IVF-biologists make almost daily phone calls to the patients. Every time they have checked the appearance of the embryos, they try to communicate it to the patients. As I recorded in my field notes from the lab, the lab personnel routinely picked up the phone during the day to make phone calls to the patients, or to answer their calls. In these discussions between the IVF-biologists and the patients, patients wanted to know whether the fertilization has occurred and resulted in at least one viable embryo. Hence, the staff explained to the patients how the embryos are developing. This kind of communication is also what the customers of private clinics expect: 
Linda is a 37-year-old woman who has experienced various IVF cycles. In the peer-support group for the childless, Linda opens up a discussion by sharing that her respect for the medical professional has decreased. Linda explains that she has read about embryo quality from the online forum of an association for the involuntary childless. She is disappointed that her doctor has not explained these things to her and her male spouse spontaneously. Instead, Linda has had to ask herself after a failed IVF, "were they [transferred embryos] top quality or not?". Another group member reacts by recommending her own doctor. Her doctor has explained embryo quality issues patiently, detail by detail to her. (Field notes from peer-support group, January 2014.)

According to previous research, the experts of embryo selection have a key role in clarifying embryo viability to patients. The patterns of doing this affect the patients' decisions, for example, concerning a possible donation of spare embryos to stem cell research. (Parry, 2006; White and Bluhm, 2010.) In the interplay between patients and the lab, in the clinics where I conducted my fieldwork, IVF-biologists and physicians share their expertise on embryos. However, in the cyclic process of IVF, not just physicians and IVF-biologists, but also patients gain competence on embryo viability by taking part in the treatment and discussing about embryogenesis with each other and with physicians, biologists and nurses. As I recorded in my field notes from the peersupport groups, patients discuss about embryos that were "exceptionally good", but nevertheless did not result in a pregnancy - and about embryos that "looked miserable", but still resulted in a pregnancy. The fact that patients discuss embryo viability in detail in the peer-support groups implies how their engagement can be understood in relation to the particular, mundane technology used in the selection. It highlights the situated and practical nature of embryo viability, since biological markers of viability pertain to patients' views on the embryos. Patients' views and understanding, together with experts' views, become a part of embryo selection process, because experts are expected to share their expertise with patients - at least in the private sector.

\section{Sharing the events of embryogenesis in both therapy and peer-support}


In the process of embryo selection, the patient experience pertain to the clinical routines of observing and classifying embryos. During my fieldwork I witnessed how the events of embryogenesis become a significant factor in the lives of the patients. In order to become enrolled in the process of embryo selection, patients make sense of what is happening on the level of the cells, gametes and embryos, which eventually may have concrete effects in selecting embryos, since, from the point of view of the experts, some patients may become too eager to hear and subsequently affect the practices of selection, as the head of a laboratory told me. One of the forums for the sense-making process is a therapy session for the patients seeking professional support for coping with their infertility. The next quotation is from an interview I conducted with a psychologist who specializes in involuntary childlessness. She, like the other psychologists or psychotherapist I met, is an independent person practicing a profession in a relatively large city of Finland, but also co-operating with some of the clinics, for example, in the cases of obligatory consultation needed if donated gametes are used. In the quotation, the therapist is talking about how the bodily markers of infertility - that is, expert knowledge of, for example, why the embryos have not attached to the uterus of this particular patient - are discussed in the therapy sessions with her customers:

I sometimes ask about the quality [of gametes and embryos], and try to highlight that the quality is not so simple [...]. I have given an example, in which it has been said in the clinic that there is this poor, totally miserable looking embryo and then there is this better looking one. Should that poor embryo be put into the bin or to the womb? And when it has been transferred to the womb, it has resulted in triplets. [...] It is not that certain that that bad one would not result in something, it can nevertheless begin to divide. (An interview with a therapist, June 2014.) 
The citation shows that patients discuss embryogenesis with their possible therapists and that therapists train patients to prepare themselves to encounter the uncertainties of embryogenesis, and to take part in choosing the right embryo. This indicates that, in addition to being enrolled in the process of embryo selection in the form of sharing information, patients may encounter the pressure to have a stance on what should be done with an embryo.

In the interviews with the patients, I asked what kind of information my informants had been given about the quality of their embryos. Julia, a 34-year-old woman, who has undergone nine IVF treatments that have not resulted in a baby being born, has embodied experience of the uncertainties of embryogenesis:

Sometimes they [the staff] have said that now it looks good, and sometimes that now it is a blastocyst [...] But well, that blastocysts has not succeeded any better. And the last time I got pregnant, regardless of the fact that the embryos were not particularly good looking. (An interview with a patient, June 2014.)

Online and face-to-face peer-support groups are possible forums for sharing experiences and making sense of embryo viability (see Meskus, 2015). In the peer-support groups I observed, (mainly) women discuss the ups and downs of their personal history in treatment, and make sense of the technical details about embryos. Women share information about which kinds of embryos have resulted in a pregnancy and a baby being born. They wonder whether others become pregnant with "top" or "poor" embryos. Participants also go into more detail and exchange information about, for example, how many cells have been in other patients' embryos on day five after fertilization and what those outcomes have been. Interaction such as this makes it possible for the patients to get better understanding about what has happened and is happening with particular kinds of embryos, as described by Julia in the interview. In this sense, patients gain skills on embryo selection. 
I suggest that peer-support practices become part of the circumstances in which embryos are selected and, thus, they also shape embryo viability in the sense of embryo viability being an assemblage of multiple factors, including patients' views. In therapy and peer-support, embryos emerge as particular kinds of entities, with particular, albeit fluid, characteristics. Patients take into their own use the biological markers of viability that are teased out in the mundane selection process, and these markers become significant for them in relating to others and in making sense of their situation in treatment. As I will show below, patients may also make decisions concerning embryo transfers, which conflict with what the IVF-biologists and the clinicians would like to do, and by such means make direct interventions into the question of which embryos are the right ones to transfer. In the end, these decisions may rewrite the facts of embryo viability, since the experts may reconsider their standards on embryo quality after surprising treatment results in following patients' decisions.

\section{A "pity transfer": transferring poor quality embryos because the patient wishes it}

The final phase of embryo selection closes the case for every IVF cycle: embryos are transferred in the hope of a pregnancy (and ultimately a child being born), or they are disposed of. In my fieldwork clinics, the IVF-biologists and the clinicians mostly hold the expert position of power to determine what to do with the embryos. The negotiations with the patients were usually restricted to distributing information to the patients. In the following, I nevertheless focus on patients' role in conducting embryo selection, as the expert informants reported to me also about cases, where the decision is ultimately made by the patient. Indeed, the uncertainty of the viability of the embryo leads to both the clinical and embryology staff feeling "ambivalent about relying too strictly on the 
grading process" (Ehrich, Williams and Farsides, 2010, 2207). This allows room for the patients' decisions.

Regardless of the aims of the physicians in conducting treatment with the best possible embryos, the quality of the embryo is not a precondition to transfer it to the patient's womb. Sometimes, poor quality embryos can be transferred because the patient wishes that it be done. Although the IVFbiologists and the physicians conducting the treatment have classified a particular embryo as bad quality, the woman or couple in treatment may feel strongly that also these embryos have enough viability, and that it is better to transfer them regardless of the probable negative pregnancy test. This testifies to how embryo viability, in the end, exceeds expert knowledge. Embryo viability may mean different things for a patient than for a biologist. Nevertheless, patients make their decisions in a context where they are informed about the biological markers of viability - also in the cases where they decide to act against the experts' prognosis. Let us now focus on the practice of transferring poor quality embryos - that is, conducting pity transfers, as my expert informants call them.

In clinic 1, the laboratory is connected to the operation room via a door and a hatch, from where the instruments are handed to and received from physicians. Before the transfer, the IVF-biologist goes to the operation room and makes sure that the identity number of the woman in the operation table matches the cells used in fertilization. In this event, the biologist shares information about the embryo although, as the head of clinic 1 joked, the information serves more as a reminder "to the dumb physicians". The patients may be well informed about the quality of the embryo at hand also before the transfer. 
The decision to transfer an embryo or not is not always clear-cut, as elaborated by a nurse in an interview:

But sometimes you have a feeling that well, when those embryos are classified, and that is a laboratory thing, so they have certain criteria for how to select and de select, and those that are no good for transfer. But it feels like no matter what we do, nature decides, we can't, since we can't see inside of an embryo obviously, we can only see what it looks like from the outside, and how it has behaved in a certain time frame, and its cleavage rate. But then it is always a surprise, that it was sort of, so to speak, a pity transfer, since we didn't have anything else, let's transfer this one. And then after all it results in a pregnancy. And then when we have transferred a high quality, top embryo it may still not begin [the pregnancy]. (An interview with a nurse, May 2013.)

Later in the interview, it became evident that patients are the ones who may prefer pity transfers instead of the disposal of inviable embryos. As also another informant, an IVF-biologist, explained to me, patients may choose to "get to the point of" embryo transfer although the embryos would not look particularly good in quality. Then embryo transfer is conducted. Poor quality embryos may get transferred, if the clinical team does not have any other embryo to use, and because it is difficult to reach a certainty that these embryos have no potential to become babies. Sometimes they do result in a pregnancy, as told by the nurse above. The category of a pity transfer exemplifies how patients are, discreetly, enrolled in the practices of selecting embryos by deciding what they want to do with the seemingly poor quality embryos. By making these decisions, patients' actions add to the enactment of embryo viability.

Patients' agency during IVF is not, however, a simple issue. Patients are driven by both feelings of exploitation and empowerment when they enter the world of IVF (Cussins, 1996; Franklin, 1997; 2013; Thompson, 2005). In embryo selection, I suggest, patients nevertheless have an important role in determining whether an embryo is ultimately assessed as viable or not, when the fate of the 
embryo is discussed and implemented. This does not mean that patients would feel like being in powerful positions, and often the situation is quite the opposite. It seems clear, however, that patients' silent choices nevertheless occur, that they are added to the embryo viability. These hopes can turn inviable embryos into ones that get transferred, as discussed further in the citation, where the nurse answers my question about pity transfers:

The researcher: So those pity transfers, like you said, so you go over it with the patient that these embryos seem like, that they're not necessarily that good, but you transfer anyway?

A nurse: Yes, and so we ask if the patient wants us to transfer. That there isn't anything else to offer, and even if there weren't that many cells and then it became a bad looking embryo, all we have are only these, and we can't... But then you have to tell them that the likelihood for a pregnancy is small or even non-existing sometimes. But for some it can be hard to think that those embryos would be thrown into some bin. Some have an emotional bond even to that one [a bad quality embryo], that there still is life in it, so some of them don't want to [dispose of an embryo]. They want to make the transfer and it can be made. (An interview with a nurse, May 2013.)

After the interview with the nurse, I also discussed the concept of pity transfers with the physicians and IVF-biologists working in the other clinics that took part in my study. Pity transfers as a practice of conducting transfers with poor quality embryos, because the patient wishes it to be done, were recognized in the field. As the interview with the nurse testifies, and as also discussed in the other interviews, the biomedical teams of the clinics nevertheless want the patients to know that, in these cases, the transfer, which adds to the total cost of the treatment for the patient, is made with an embryo with low chances of implantation (from the discussion on informed consent, see Sugarman et al, 1999). As I discussed further with the head of the laboratory of clinic 1, the clinics also have to think about their success rates; they need to submit their annual reports to the Finnish National Institute for Health and Welfare. In this respect, transferring poor quality embryos with low chances 
of implantation is not in the interests of the clinic, as reported by the IVF-biologist. Nevertheless, in private clinics, these transfers occur.

From the perspective of enacting embryo viability, conducting pity transfers challenges the clearcut division between an embryo as a potential child or something that can be disposed of. However, it does more than that. Pity transfers may result in pregnancies, as testified by the nurse above. The IVF-biologists, whom I interviewed after the nurse, further explained how, in the working world of the lab, conceptions about embryo quality change as a result of conducting selection and transfers in practice. As discussed earlier in the paper, for example, the head of clinic 1 told me that earlier in their clinic, the embryos with multiple nucleuses "were mostly always discarded", but "when these [embryos] have been transferred", it has come about that they might nevertheless be viable, since pregnancies have begun. Pity transfers are examples of cases when poor quality embryos may end up being chosen to be transferred. In other words, when the transferring of poor quality embryos result in healthy children being born, as discussed by the nurse and the IVF-biologist, the clinics may reconsider the criteria of grading embryos. A loop between experts' criteria and patients' actions emerge: patients affect the production of scientific facts on embryo quality (cf. Rabeharisoa et al, 2014).

Exploring the category of pity transfers shows, firstly, that patient participation in embryo selection can rewrite the facts of embryo quality: poor quality embryos may be enacted as viable by transferring them to the uterus. If these transfers result in pregnancies, the quality criterions may then be reconsidered. Secondly, analysing pity transfers shows that embryo viability is more than the quality of the embryos estimated in the lab. Embryo viability is negotiated with patients. It is composed of scientific facts, laboratory practices and patients' decisions. 


\section{Conclusion}

In this paper, I have elaborated the idea of embryo viability as an enactment of the scientific facts on embryo quality, the expert knowledge and laboratory practices, and the patients' engagement in the process of selection. I have analysed embryo viability as an achievement that hinges upon several factors in addition to the quality estimation of an embryo. The contested character of viable or inviable embryos in relation to their use has been shown in several studies, to which my study contributes (Ehrich et al, 2010; Roberts, 2007; Svendsen and Koch, 2008). In comparison to previous research on selective reproductive technologies (SRTs), I have analysed the multiple aspects of the routine embryo selection, and my analysis highlights the negotiation involved in the mundane art of selection that is not, for example, conducted on genetic grounds. In relation to the variety of techniques in assessing embryo viability, this paper elaborates how the viability reflects the technology used in its achievement. An embryo may be enacted as viable by the eye, but not after analysing a PGD/PGS sample. These different enactments have profound implications for "the legal, moral, maternal and political properties" (Cussins, 1996, 587) of the embryos.

In addition, this paper elaborates how patients engage with the specific, mundane technology by adopting information, gaining skills, and by making interventions (in the case of the so-called pity transfers). In future research, the analysis of this paper could be complemented by exploring patients' accounts of how they make decisions, since the emphasis in this paper has been more on the practices of patient enrolment into the issues of embryo quality, and on how embryo viability could be understood as a process exceeding expert knowledge.

This paper has worked with the basic idea of the concept of enactment: that embryos and their viability are inseparable from the matters of laboratory life. After the pioneering contributions of 
lab ethnographies have stabilized their place in the methodological apparatus of STS, it is perhaps easy to relate to the idea that, for example, microscopes enact what the embryos can be in the lab. According to this understanding, embryo viability is enacted in the practices of embryo selection, for example, when a biologist writes inscriptions about the details of embryogenesis. However, the point of this paper has been to explore what happens also outside the clinic as the process of enacting embryo viability. In other words, to understand, for example, a discussion in a peersupport group between two women suffering from infertility as something that has implications for the selection process, opens up further insight into both embryo selection as a process and onto the ways the concept of enactment can be applied. Furthermore, following the process of enactments beyond the walls of the clinics shows how the sense-making in constructing science in labs pertains to the sense making of the patients - and vice versa.

In relation to the internality-externality discussion in laboratory studies, this paper highlights the role of external factors as affecting the selection practices in the lab, in this case patients' complex lives and decisions in understanding what happens in the situated settings of labs. By doing this, the analysis shows that it is beneficial to follow the enactments of objects or entities, such as embryos, also beyond the falls of labs, clinics and hospitals. Here, a multi-sited fieldwork provides new insight also into events that are seemingly confined to the specific realms of buildings, rooms and treatment procedures.

\footnotetext{
${ }^{1}$ IVF has been a routine treatment in Finland since the end of the 1980s (Malin and Hemminki, 1996, 975). Finland has been a late legislator in the area of reproduction and, thus, a rather liberal country, when it comes to ART and the implementation of new techniques (Eriksson, 2017; Meskus, 2015, 73). Since 2006, however, the Finnish act on assisted fertility treatments has directed the ways ART services are organized in Finland. Treatments are available for male-female couples, female-female couples and single women. However, the law bans surrogacy that was previously unofficially permitted in Finland (Act on Assisted Fertility Treatments, 2006). Concerning ARTs, the Finnish economy
} 
of healthcare is driven by both the public and the private sector. The role of the private sector is relatively large (see National Institute for Health and welfare, 2017). Concerning embryo selection, Finland provides a good case for analysing the mundane aspect of it in a context where multiple embryo transfers are avoided, in order to overcome the medical risk of zygotic twins. The one embryo policy, which is applied widely also in other Nordic countries (TemaNord, 2006), is based on transferring a single embryo at a time to the woman's uterus. However, it is argued that since the embryo is carefully chosen, the probability for pregnancy will not decrease (Martikainen et al, 2001). ${ }^{2}$ Existing discussions focusing on the everyday part of selection have nevertheless elaborated, especially, on how embryos become 'extra' or 'spare' in terms of IVF and are therefore donated to, for example, stem cell research (Franklin, 2006; Ehrich et al, 2010; Svendsen and Koch, 2008).

3 Margaret Lock and Vinh-Kim Nguyen $(2010,93)$ argue that "the biological sciences produce real but partial pictures of what is under examination", and that "these 'snapshots' are usually understood by involved scientists as different representations of the same ontological reality”. In line with Lock and Nguyen, and following Sarah Franklin's (2013) idea of "biological relativity", however, in this paper, these snapshots are "understood as lenses onto a shifting and contingent reality" (Lock and Nguyen 2010, 93).

${ }^{4}$ In clinics 1 and 2, the experts involved in selecting embryos are physicians and biologists/geneticist/ laboratory technicians. I will refer to all of the experts working in the lab as IVF-biologists. 


\section{References}

Act on Assisted Fertility Treatments, 22 December 2006/1237.

ALPHA and ESHRE (2011) Istanbul Consensus Workshop on Embryo Assessment: Proceedings of an Expert Meeting. Reproductive Biomedicine Online 22(6): 632-646.

Cussins, C. (1996) Ontological Choreography: Agency through Objectification in Infertility Clinics. Social Studies of Science 26(3): 575-610.

Doing, P. (2008) Give Me a Laboratory and I Will Raise a Discipline: The Past, Present and Future on Laboratory Studies in STS. In: E.J. Hackett, O. Amsterdamska, M. Lynch and J. Wajcman (eds.) The Handbook of Science and Technology Studies. Cambridge, Massachusetts, London and England: The MIT Press, pp. 279-295.

Ehrich, K., Williams, C., Farsides, B., Sandall, J. and Scott, R. (2007) Choosing embryos: ethical complexity and relational autonomy in staff accounts of PGD. Sociology of Health and Illness 29(7): 1091-1106.

Ehrich, K., Williams, C. and Farsides, B. (2008) The embryo as moral work object: PGD/IVF staff views and experiences. Sociology of Health and Illness 30(5): 772-787.

Ehrich, K., Williams, C. and Farsides, B. (2010) Fresh or frozen? Classifying 'spare embryos for donation to human embryonic stem cell research. Social Science \& Medicine 71(2010): 2204-2211. 
Eriksson, L. (2017) Finland as a late Regulator of Assisted Reproduction: A Permissive Policy under Debate. In: M Lie, and N. Lykke (eds.) Assisted Reproduction Across Borders. Feminist Perspectives on Normalization, Disruptions and Transmissions. New York and London: Routledge; pp. 124-136.

Falzon, M. (2009) Multi-sited ethnography: Theory, Praxis and Locality in Contemporary Research. Farnham: Ashgate Publishing.

Franklin, S. (1997) Embodies Progress. A Cultural Account of Assisted Conception. London: Routledge.

Franklin, S (2006) Embryonic Economies: The Double Reproductive Value of Stem Cells. BioSocieties 1(1): 71-90.

Franklin, S. (2013) Biological Relatives. IVF, Stem Cells, and the Future of Kinship. Durham and London: Duke University Press.

Franklin, S. and Roberts, C. (2006) Born and Made. An Ethnography of Preimplantation Genetic Diagnosis. Princeton and Oxford: Princeton University Press.

Gammeltoft, T. M. and Wahlberg, A. (2014) Selective Reproductive Technologies. The Annual Review of Anthropology 2014(43): 201-216. 
Gardner, D. K., Lane, M., Stevens, J., Schlenker, T. and Schoolcraft, W. B. (2000) Blastocyst Score Affects Implantation and Pregnancy Outcome: Towards a Single Blastocyst Transfer. Fertility and Sterility 73(6): 1155-1158.

Hannerz, U. (2003) Being there... and there... and there! Reflections on multi-site ethnography. Ethnography 4(2): 201-216.

Hashiloni-Dolev, Y. and Shkedi, S. (2007) On new reproductive technologies and family ethics: Pre-implantation genetic diagnosis for sibling donor in Israel and Germany. Social Science and Medicine 65, 2081-2092.

Helén, Ilpo (2011) The depression paradigm and beyond: The practical ontology of mood disorders Science Studies 24(1): 82-112.

Huijer, M. (2009) Storytelling to Enrich the Democratic Debate: The Dutch Discussion on Embryo Selection for Hereditary Breast Cancer. BioSocieties 2009(4), 223-238.

Knorr-Cetina, K. (1981) The Manufacture of Knowledge. An Essay on Constructivist and Contextual Nature of Science. Oxford: Pergamon Press.

Kieslinger, D. C., De Gheselle, S., Lambalk C. B., De Sutter, P., Kostelijk, E. H., Twisk, J. W. R., Van Rijswijk, J., Van den Abbeel, E., Vergouw, C. G (2016) Embryo selection using time-lapse analysis (Early Embryo Viability Assessment) in conjunction with standard morphology: a prospective two-center pilot study. Human Reproduction 21(11), 2450-2457. 
Latour, B. (1983) Give me a laboratory and I will raise the world. In K. Knorr-Cetina and M. Mulkay, M. (eds.) Science Observed: Perspectives on the Social Study of Science. London: Sage, pp. 141-170.

Latour, B. and Woolgar, S. (1986) Laboratory Life. The Construction of Scientific Facts. Princeton: Princeton University Press.

Law, J. (2010 [2004]) After Method: Mess in Social Science Research. New York and London: Routledge.

Lie, M. (2015) Reproduction inside/outside: Medical imaging and the domestication of assisted reproductive technologies. European Journal of Women's Studies 22(1): 53-69.

Lie, M. and Lykke, N. (2017) Editorial Introduction: Assisted Reproduction Across Borders: Feminist Perspectives on Normalizations, Disruptions and Transmissions. In: M Lie and N. Lykke (eds.) Assisted Reproduction Across Borders. Feminist Perspectives on Normalization, Disruptions and Transmissions. New York and London: Routledge; pp. 1-21.

Lock, M. and Nguyen V-K. (2010) An Anthropology of Biomedicine. Malden, Oxford and West Sussex: Wiley-Blackwell.

Lynch, M. (1985) Art and Artifact in Laboratory Science. A Study of Shop Work and Shop Talk in Laboratory Science. London: Routledge and Kegan Paul. 
Malin, M. Silverio and Hemminki, E. (1996) Practice of in-vitro fertilization: a case study from Finland. Social Science \& Medicine 42(7): 975-983.

Marcus, G. E. (1995) Ethnography In/of the World System: The Emergence of Multi-Sited Ethnography. Annual Review of Anthropology 24(1): 95-117.

Martikainen, H., Tiitinen, A., Tomás, C., Tapanainen, J., Orava, M., Tuomivaara, L., Vilska, S., Hydén-Granskog, C., Hovatta, O. and the Finnish ET Study Group (2001) One versus two embryo transfer after IVF and ICSI: a randomized study. Human Reproduction 16(9): 1900-1903.

Martin, L.J. (2014) The World's Not Ready for This: Globalizing Selective Technologies. Science, Technology \& Human Values 39(3): 432-455.

Meskus, M. (2012) Personalized ethics: The emergence and the effects in prenatal testing. BioSocieties 7(4): 373-392.

Meskus, M. (2015) Agential multiplicity in the assisted beginnings of life. European Journal of Women's Studies 22(1): 70-83.

Meskus, M. (2018, in production) Craft in Biomedical Research: The iPS Cell Technology and the Future of Stem Cell Science. Basingstoke and New York: Palgrave Macmillan.

McGowan, M.L and Sharp, R.R. (2013) Justice in the Context of Family Balancing. Science Technology and Human Values 38(2): 271-293. 
Mol, A. (2002) The Body Multiple: Ontology in Medical Practice. Durham, NC: Duke University Press.

Mol, A. (2008) The Logic of Care: Health and the Problem of Patient Choice. Abingdon, Oxon, New York: Routledge.

National Institute for Health and Welfare (2017) Statistical report. Assisted fertility treatments 2015-2016, http://urn.fi/URN:NBN:fi-fe201704136108, accessed 19 September 2017.

Nisker, J., Baylis, F., Karpin, I., McLeod, C. and Mykitiuk, R. (eds.) (2010) The 'Healthy' Embryo. Social, Biomedical, Legal and Philosophical Perspectives. Cambridge: Cambridge University Press.

Parry, S.(2006) (Re)constructing embryos in stem cell research: Exploring the meaning of embryos for people involved in fertility treatments. Social Science \& Medicine 62(2006): 2349-2359.

Pavone, Vincenzo and Arias, Flor (2012) Beyond the Geneticization Thesis: The Political Economy of PGD/PGS in Spain. Science, Technology and Human Values 37(3): 235-261.

Rabeharisoa, V., Moreira, T. and Akrich, M. (2014) Evidence-based activism: Patients', users' and activists' groups in knowledge society. BioSocieties 9(2): 111-128.

Roberts, E.F.S. (2007) Extra embryos: The ethics of cryopservation in Ecuador and elsewhere. American Ethnologist 31(1): 181 -199. 
Rothman, B. K. (1986) The Tentative Pregnancy: Prenatal Diagnosis and the Future of Motherhood. New York: Viking Press.

Scully, L.J., Banks, S. and Shakespeare, T.W. (2006) Chance, choice and control: Lay debate on prenatal sex selection. Social Science and Medicine 63(2006): 21 -31.

Sugarman, J., McCrory, D.C., Powell, D. (1999) Empirical research on informed consent: an annotated bibliography. A Hastings Center Report, Special Supplement.

Squier, S. M. (2004) Liminal Lives: Imagining the Human at the Frontiers of Biomedicine. Durham: Duke University Press.

Svendsen, M.N. and Koch, L. (2008) Unpacking the 'Spare Embryo': Facilitating Stem Cell Research in a Moral Landscape. Social Studies of Science 38(93): 93-110.

TemaNord (2006:505) Assisted Reproduction in the Nordic Countries. Copenhagen: Nordic Council of Ministers.

Thompson, C. (2005) Making Parents: the Ontological Choreography of Reproductive Technologies. Cambridge: MIT Press.

Van de Wiel, L. (2017) Cellular Origins: A Visual Analysis of Time-Lapse Embryo Imaging. In: M Lie and N. Lykke (eds.) Assisted Reproduction Across Borders. Feminist Perspectives on Normalization, Disruptions and Transmissions. New York and London: Routledge; pp. 288-301. 
Wahlberg, A. and Gammeltoft T. M. (2018) Introduction: Kinds of Children. In: Wahlberg, A. and Gammeltoft T. M. (eds.) Selective Reproduction in the 21 st Century. Basingstoke and New York: Palgrave Macmillan; pp. 1-24.

White, A. and Bluhm, R. (2010) Embryo health and embryo research. In: J. Nisker, F. Baylis, I. Karpin, C. McLeod, and R. Mykitiuk (eds.) The 'Healthy' Embryo. Social, Biomedical, Legal and Philosophical Perspectives. Cambridge: Cambridge University Press, pp. 187-199.

Wittel, A. (2000) Ethnography on the Move: From Field to Net to Internet. Forum: Qualitative Social Research 1: 1 Art. 21, http://www.qualitativeresearch.net/index.php/fqs/article/viewArticle/1131/2517, accessed 1 January 2010. 